\title{
Demarketing para a Redução de Consumo de um Bem Natural, Escasso e Essencial: a
} Água.

Carmen Lidia Ramuski

DOI - 10.25160/v5i2.d3

\section{Introdução}

Questões sociais e ambientais estão orientando tanto a oferta de produtos por parte das organizações, como um comportamento responsável por parte dos consumidores, mas, nem todos os bens ofertados ao mercado, são alvo de um incentivo à demanda. Por vezes, a redução de consumo é necessária como no caso de matérias-primas escassas, produtos prejudiciais à saúde ou que serão descontinuados e recursos naturais não substituíveis ou não renováveis (KOTLER; LEVY, 1971; MENON; MENON, 1997; KOTLER, 1974; CULLVICK, 1975; GRINSTEIN; NISAN, 2009; SOHDI, 2011).

Para estas situações, campanhas de demarketing são realizadas com o mesmo mix do marketing tradicional, mas com as estratégias aplicadas no sentido inverso, como, por exemplo, um aumento de preço em vez de uma promoção de vendas; uma redução no budget promocional ao invés de um aumento, ou ainda uma redução na distribuição no lugar de uma busca por maior participação de mercado (KOTLER, LEVY, 1971). Uma campanha de demarketing traz ainda um desafio adicional, que é o de reduzir o consumo de algum bem, sem prejuízo à receita da organização, uma vez que esta continuará a necessitar de recursos para responder a seus acionistas e/ou realizar investimentos que garantam a continuidade de seu negócio.

A companhia de água que abastece a maior cidade brasileira - São Paulo, diante de um cenário climático atípico, no biênio 2014/15, implementou uma campanha caracterizável como demarketing, com várias ações que atuaram durante certo tempo, concomitantemente, visando a tornar o consumidor mais consciente sobre o consumo da água e a obter uma resposta que impedisse que o abastecimento local, em hipótese alguma, fosse totalmente interrompido. Intensa campanha promocional, estímulos financeiros e uma distribuição diferenciada de água foram as ações implementadas para atingir de forma rápida o objetivo desejado. Além desses, havia um estímulo natural e maior instalado, que levava à urgência de resultados - uma longa estiagem aliada à altas temperaturas que favoreciam um consumo elevado de água e contribuíam com o rebaixamento do nível do maior reservatório da cidade. 
Para uma melhor compreensão da situação, será apresentado, a seguir, uma revisão teórica sobre o tema demarketing; as ações realizadas pela companhia de água juntamente com o governo do estado de São Paulo, que é seu maior acionista e, na sequência, uma análise dessa campanha, em relação à teoria original de Kotler e Levy (1971).

\section{Referencial Teórico}

\section{1 - Demarketing}

Demarketing "é a parte do marketing (...) que objetiva desencorajar os clientes em geral ou parte deles (...) de forma temporária ou permanente" (KOTLER; LEVY, 1971) a consumir algum bem.

Kotler e Levy (1971) identificam três tipos de demarketing: a) o geral, quando se deseja reduzir a demanda total; b) o seletivo, quando a redução é para uma parte de consumidores, mas não para outras; c) o ostensivo, quando, ao contrário, pretende-se estimular a demanda tornando o produto raro, difícil de ser obtido. Os autores também mencionam três situações mais comuns em que o demarketing pode ser aplicado: quando há escassez de um bem, quando o produto sofre de uma superpopularidade crônica ou quando se pretende eliminá-lo definitivamente. O objeto deste estudo é uma campanha que visou à redução do consumo de água incluindo-se, portanto, no tipo "demarketing geral" e em uma situação de "escassez temporária".

Conforme Kotler e Levy (1971) demarketing utiliza-se das mesmas "políticas do marketing tradicional" - produto, preço, praça e promoção, ou seja, do mesmo mix de marketing assim como dos mesmos "instrumentos clássicos", ou seja, das mesmas estratégias, mas, no caso de demarketing, estas estratégias são utilizadas em sentido contrário, tais como um aumento de preço ao invés de uma redução; uma diminuição da rede de distribuição, ao invés de uma expansão e um corte nos investimentos promocionais, ao invés de um incremento, uma vez que o objetivo não é o aumento mas sim a diminuição da demanda por um bem.

Entre estes instrumentos, entende-se que o preço possa ser o mais complexo para ser gerenciado e o de maior impacto junto à organização e ao consumidor. Para o consumidor, preço é complexo por ser o componente do mix de marketing mais tangível e perceptível; qualquer alteração, por menor que seja, será muito mais percebida, pelo consumidor, que uma melhoria no produto, apresentada em igual proporção. Para uma organização, preço é complexo porque envolve várias decisões, particularmente quando se 
trata de uma elevação e não de uma redução em seu patamar, envolvendo questões como: em quanto deverá importar o aumento, quando será implementado, como enfrentar situações em que existam limitações ou barreiras para esse aumento (governo, concorrência e sensibilidade dos próprios clientes) ou como justificar essa alteração de preço para o consumidor (KOTLER, 1986; 1974).

Kotler e Levy (1971) ressaltam a necessidade de se verificar, previamente, quão sensíveis os clientes são a cada instrumento que a organização pretende utilizar para deter a demanda, assim como, quais efeitos eles produzirão, quando forem aplicados conjuntamente, visando a evitar uma superinibição de clientes e, consequentemente, uma difícil recuperação, quando a situação não mais exigir uma campanha de demarketing. Suh, Rho e Greene (2012) também mencionam que pesquisas de demarketing necessitam investigar diferentes combinações do mix de demarketing, verificando como os consumidores reagem a diferentes estímulos, enquanto Cullwick (1975) e Munish, Payal e Priya (2014), alertam ser necessário "a organização conhecer mais, e não menos" a respeito dos efeitos de suas ações no relacionamento com os clientes.

Estudos sobre Demarketing são raros. Deutsch e Liebermann (1985) já apontavam o reduzido número de estudos sobre o assunto e apesar de decorridos 40 anos da apresentação dos conceitos fundamentais de demarketing, tanto Sodhi (2011) como Suh, Rho e Greene (2012), entre outros, confirmam a imutabilidade dessa situação, mencionando, ainda, que os estudos encontrados se referem mais às campanhas antitabagistas - como as relatadas por Pechmann et al. (2003) e Andrews et al. (2004), que, em geral, são patrocinadas pelo governo ou por organizações não governamentais, com finalidade social.

Essa situação não foi alterada nos últimos anos. Poucos foram os artigos encontrados na literatura que tratam expressamente de demarketing, como os relacionados a serviço (LAWTHER; HASTINGS; LOWRY, 1997); a posicionamento (CULLWICK, 1975); à sustentabilidade e gestão ambiental (GESTNER; HESS; CHU, 1993; SODHI, 2011); a relacionamento e retenção de consumidores (GORDON, 2006; MUNISH; PAYAL; PRIYA, 2014); à redução à visitação em locais públicos (GROOF, 1998; BEETON; PINGE, 2003; MEDWAY; WARNABY; DHARNI, 2010; ARMSTRONG; KERN, 2011); ao comportamento de grupos minoritários (GRINSTEIN; NISAN, 2009); à redução do consumo de álcool e/ou tabaco (WALL, 2005; SHIU, HASSAN, WALSH, 2006; ILNESS et al., 2007), à redução do uso do automóvel (WRIGHT; EGAN, 2000) ou de serviços médicos (ANNABELLE, 1987 apud LAWTHER, HASTINGS; LOWRY, 1997). 
Aqueles que conhecem a teoria de demarketing visualizam, muitas vezes, sua aplicação de forma oculta, pois ele não é expressamente identificado como tal e, quando se destina a redução de consumo de um bem que prejudique os indivíduos ou a uma sociedade, tende a ser mais relatado com o foco restrito de uma campanha de marketing social.

Entende-se que este seja um dos motivos que colabore para a escassez de trabalhos sobre o assunto pois, à medida que uma campanha é analisada sob o foco de marketing social deixa de ser visualizada como uma campanha de demarketing, perdendo-se a amplitude de suas aplicações, bem como de seus instrumentos e efeitos.

Embora esse não seja um dos objetivos deste trabalho, é importante que se destaque que demarketing apresenta um âmbito maior do que marketing social, estando este último nele incluso. Algumas diferenças que podem ser destacadas entre demarketing e marketing social (KOTLER; ZALTMAN, 1971; KOTLER; LEVY (1971); KOTLER, 1974; SODHI, 2011) são: a) enquanto marketing social visa a uma modificação de comportamento das pessoas que possam prejudicar a elas mesmas ou a sociedade, demarketing tem como objetivo prioritário a redução da demanda de algum bem, tenha essa redução de demanda alguma relação ou não com uma finalidade social; b) os objetivos de marketing social são contínuos - sempre se estimulará o abandono ao fumo ou a redução da poluição, por exemplo, enquanto os objetivos de demarketing podem se referir a eliminação definitiva de um bem ou a uma supressão temporária; c) ações de marketing social visam necessariamente a um benefício social, enquanto ações de demarketing podem ser realizadas para fins sociais, ambientais ou comerciais.

Com isto, a campanha de demarketing, aqui estudada, apresenta-se como um raro, peculiar e importante aprendizado sobre o assunto, uma vez que: a) a campanha se enquadra como sendo do tipo "geral", causada por uma "escassez" temporária do produto; b) foi patrocinada por uma organização de economia mista - a companhia responsável pela distribuição de água possui de um lado o governo (ÁGUA...,2015) e de outro acionistas - não tendo sido, portanto, ação com patrocínio exclusivamente estatal; c) as ações desenvolvidas para a campanha não visavam somente a evitar um prejuízo maior à sociedade, mas também a equacionar uma questão empresarial, uma vez que a água é o principal "produto" para a receita da companhia responsável por sua distribuição, cujos acionistas esperam resultados positivos; d) água é um bem com elasticidade extremamente baixa e para se ter sucesso com esta categoria de produto, a campanha de demarketing precisa ser muito mais forte que a resistência que os consumidores apresentam (GRISNTEIN; NISAN, 2009); e) as ações realizadas não se apoiaram, como é costume, em 
apenas um componente do mix mercadológico - a promoção por meio de veiculação intensa (DEUTCH; LIEBERMANN, 1985); f) houve ações relacionadas à precificação, com incentivos a quem consumisse menos e multas a quem aumentasse o consumo, além de dois aumentos no preço; g) as funções de utilidade da distribuição ${ }^{1}$ é que foram alteradas, uma vez que a companhia responsável pela distribuição de água opera de forma exclusiva, e, portanto, o número de distribuidores não poderia ser reduzido, conforme recomendam Kotler e Levy (1971), nem o bem ofertado poderia ser suprimido, por ser essencial à vida.

Além disso, as ações realizadas atuaram de forma concomitante, durante a maior parte do tempo, trazendo um efeito indesejado, mas diferente do previsto por Kotler e Levy (1971) - o risco de uma superinibição dos clientes.

\section{2 - O Comportamento do Consumidor e Fatores de Influência em seu Comportamento no Consumo da Água}

Antes da crise de abastecimento de água, os consumidores residentes na cidade de São Paulo e em municípios vizinhos, componentes da denominada Região Metropolitana de São Paulo, apresentavam uma atitude e um comportamento correspondente à situação e ao ambiente em que viviam. A região nunca havia vivido tão importante falta de água, ao contrário, no verão, eram comuns as "trombas d'água" com inundações que deixavam vários desabrigados com perdas totais de seus bens, grandes áreas intransitáveis e risco iminente de transbordamento de reservatórios (REPRESAS..., 2010). A água era produto abundante, utilizado para diversos fins e sem muito pensar, bastava abrir-se qualquer torneira que ela estava disponível, na quantidade e pelo tempo desejados, com um baixo preço. Portanto, mais que mudar a atitude do consumidor era necessário mudar seu comportamento imediatamente.

A atitude é uma avaliação geral e duradoura que as pessoas fazem de algo, o que elas pensam sobre um objeto (SOLOMON, 1996) enquanto o comportamento é uma decorrência dessa atitude, desta forma, se alguém possui uma atitude favorável à preservação do meio ambiente é provável que se engaje, por exemplo, em ações de reciclagem e aquisição de produtos "verdes", ou seja, seu comportamento corresponderá a atitude que ela possui (SHETH; MITTAL; NEWMAN, 1999).

\footnotetext{
${ }^{1}$ As funções de utilidade da distribuição são: tempo - o produto deve estar disponível no momento que o consumidor desejar; lugar - o produto precisa estar disponível onde o cliente quiser obtê-lo; posse - o consumidor precisa poder possuir o produto (DIAS, 2003).
} 
Antes da crise, a água era considerada pelos moradores como um recurso natural e suficiente para todos, podendo ser utilizada à vontade e o comportamento apresentado por eles correspondia a essa atitude, o consumo era realizado de forma irresponsável, incorrendo, muitas vezes, em desperdício. A utilização de água potável para lavar calçadas, jardins, quintais e veículos, era ato corriqueiro e o esguicho, por vezes, exercia a função de vassoura - a força do jato de água é que retirava a poeira e/ou sujeira de locais e objetos, o que levou Lemos² a classificar este ato como uma "tecnologia tupiniquim" e considerá-lo "o maior absurdo do mundo" (SHALOM, 2014).

Quando a crise surgiu (SEM..., 2014), foi necessário que a companhia de água e o governo do estado desenvolvessem uma campanha intensa e urgente, pois o consumidor precisava reduzir seu consumo com a maior brevidade possível; não se tratava apenas de uma mudança em sua atitude (em seu modo de pensar), o que em geral ocorre a longo prazo, por meio de reeducação e conscientização, mas, sim de uma mudança imediata de seu comportamento (em seu modo de agir); precisava haver um corte incisivo e instantâneo em sua forma de consumo.

Foram então estabelecidos estímulos para que o consumidor tivesse motivos para modificar sua atitude e, principalmente, seu comportamento, de forma imediata, uma vez que, conforme Solomon (1996) atitudes são formadas por motivos e cada pessoa tem pelo menos um, favorável ou desfavorável, para considerar a respeito de algo.

Os estímulos para motivar essa redução foram: a) uma campanha intensa, com peças publicitárias veiculadas em meios de comunicação de massa e/ou impressas, além de contatos pessoais realizado entre agentes da companhia de água e o público-alvo (CHESS, 2015), que visava a um aumento da consciência ambiental dos consumidores com relação a este recurso que se apresenta escasso, de forma geral, e precisa ser economizado sempre, não somente em época de crise; b) um conjunto de descontos para quem reduzisse o consumo, de multas para quem o aumentasse e aumentos de preços reais (NÍVEL..., 2014), constituindo-se em motivo racional e eficaz, principalmente junto aos consumidores sensíveis a preço; c) um controle no fornecimento, que resultava em uma alteração na disponibilidade da água de full para part-time e diminuía a pressão da água fornecida (SABESP, 2015b, SORANO, 2015b), o que dificultava o aumento de consumo e seu armazenamento. Além desses, havia um motivo de ordem natural - a falta de chuvas que causava uma queda importante no nível do maior reservatório da cidade, o Cantareira, embora o intenso calor estimulasse um consumo em maior nível que o habitual, durante o alto verão.

\footnotetext{
${ }^{2}$ Haroldo Mattos de Lemos - presidente do Comitê Brasileiro das Nações Unidas para o Meio Ambiente (SHALOM, 2014).
} 
O único estímulo, entre esses, que poderia mudar a atitude do consumidor, era a comunicação, uma vez que, conforme Mowen e Minor (1988) mensagens veiculadas provocam uma resposta cognitiva ${ }^{3}$ nas pessoas, embora essa resposta possa não ocorrer com a urgência que se necessite. Os outros estímulos são considerados temporários, por Shiffman, Kanuk (2000) e Mowen e Minor (1998), e, como tal, capazes de promover mudança de comportamento, mas não de atitude; por isso, quando deixam de existir, também interrompem seus efeitos e as pessoas tendem a retornar ao comportamento anterior.

\section{O Estudo}

Antes de se iniciar a descrição do cenário, é importante esclarecer que esse estudo se concentrou nas ações que foram realizadas pela companhia responsável pelo fornecimento de água e/ou o governo do estado da região estudada, considerando apenas o que poderia caracterizar uma campanha de demarketing geral e temporária de um bem em situação de escassez. Visou, portanto, somente às ações de comunicação, distribuição e precificação, que podiam ser percebidas pelo consumidor e que se destinavam, exclusivamente, à redução do consumo, analisando-as sob o prisma de uma campanha de demarketing (KOTLER; LEVY, 1971; KOTLER, 1974). Não se destinou, portanto, a analisar outras ações e aspectos que poderiam ter implicado em uma gestão da crise, diferente da que foi realizada, tanto pela companhia de água como pelo governo do estado.

\section{1 - O cenário}

São Paulo é a maior cidade brasileira e sua região metropolitana abrange cerca de 20 milhões de habitantes. O sistema denominado Cantareira, que abastece quase metade dessa população, no início de 2014, começou a apresentar sinais preocupantes, pois seu nível diminuía a cada dia, de forma muito significativa (ROCHA, 2014) e sem qualquer perspectiva de melhoria iminente; o volume de chuvas registrado apresentava-se $43 \%$ abaixo da média (CHESS - CRISE HÍDRICA, ENERGÉTICA E SOLUÇÕES DA SABESP, 2015).

\footnotetext{
${ }^{3}$ Conforme Mowen e Minor (1988, p.280-281) “respostas cognitivas são pensamentos favoráveis e/ou desfavoráveis gerados como resultado de uma comunicação". Os autores também ressaltam que comunicação, no caso, deve ser entendida como qualquer aspecto de uma mensagem, incluindo suas "fontes, tipos" e meios utilizados para sua veiculação, como por exemplo, "televisão, rádio ou mídia impressa".
} 
Em uma cidade em que água não era problema, ao contrário, os últimos acontecimentos relevantes, em 2010, mencionavam o risco de as represas transbordarem (REPRESAS..., 2010), a população foi surpreendida quando se evidenciou a possibilidade de faltar água na cidade de forma significativa (SEM..., 2014). A situação emergencial sensibilizou vários meios de comunicação, assim como organizações públicas e privadas dos mais diversos portes e ramos de negócio, que passaram, elas mesmas, a cuidar, cada uma, de sua própria forma de consumir água, bem como a incentivar um consumo mais responsável por parte de funcionários, clientes e público em geral.

Tanto a companhia responsável pelo abastecimento de água da região, como o governo do estado (seu principal acionista) empreenderam um conjunto de estratégias visando à melhoria do abastecimento e à redução de consumo. As estratégias de redução de consumo eram destinadas à população e foram alvo deste estudo, no que se está denominando "Demarketing da Água". A primeira estratégia a sem implantada foi a promocional, com uma intensa comunicação e venda pessoal ${ }^{4}$, durante o biênio 2014/15, constituindo-se das seguintes ações:

a) veiculação de dez filmes, em emissoras abertas ${ }^{5}$ - o primeiro veiculado a partir de 27 de janeiro de 2014 e o último com veiculação encerrada em 30 de agosto de 2015, totalizando 773 milhões de impactos ${ }^{6}$, além de mensagens em emissoras de rádio (CHESS, 2015; SABESP, 2015);

b) peças de rua ${ }^{7}$ (CHESS, 2015);

c) veiculação de informes publicitários com caráter "instrucional" (RANGAN; KARIM; SANDBERG, 1996; GRINSTEIN; NISAN, 2006), ou seja, informativo e educativo, como ilustrado na Figura 1 a seguir;

\footnotetext{
${ }^{4}$ Entende-se que ações onde houve contato pessoal com a população possam ser classificadas como venda pessoal. Nota do autor.

${ }^{5}$ As emissoras abertas foram principalmente a Globo, a Record, a Bandeirantes, SBT, entre outras (SABESP, 2015).

${ }^{6}$ Conforme a companhia de água "impactos” significam "visualizações” (SABESP, 2015).

7 "Peças de rua" referem-se a materiais publicitários como outdoors, cartazes em abrigos de pontos de ônibus, entre outros, utilizados comumente em mídia externa/alternativa. Nota do autor.
} 


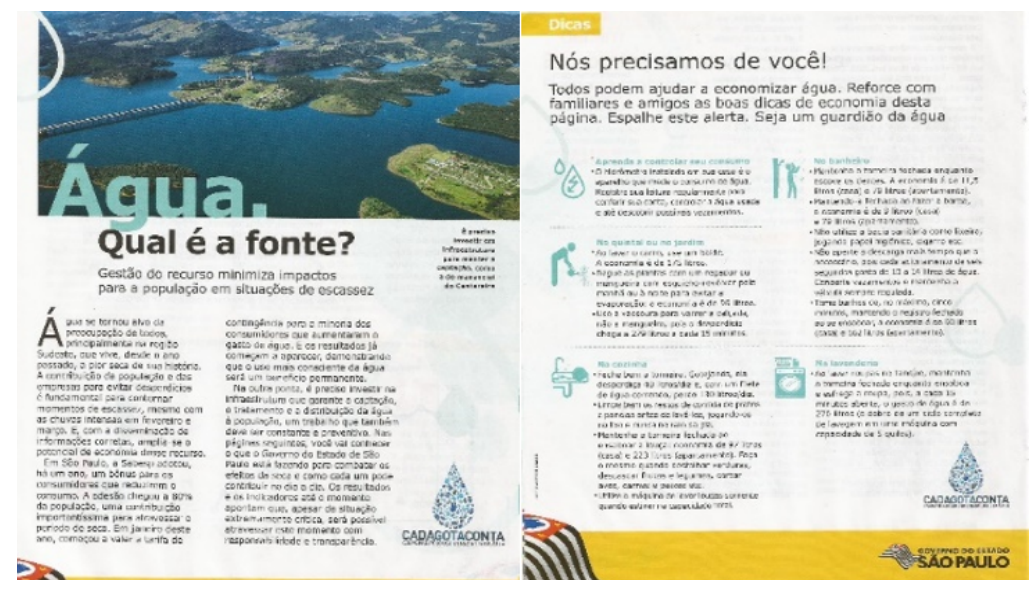

Figura 1 - Primeira e última páginas de Informe Publicitário do Governo do Estado de São Paulo. Fonte: ÁGUA... (2015). Nota: O informe continha oito páginas, sendo as sete primeiras informativas e a última educativa.

d) envio de mala-diretas aos consumidores, como a ilustrada na Figura 2 a seguir.

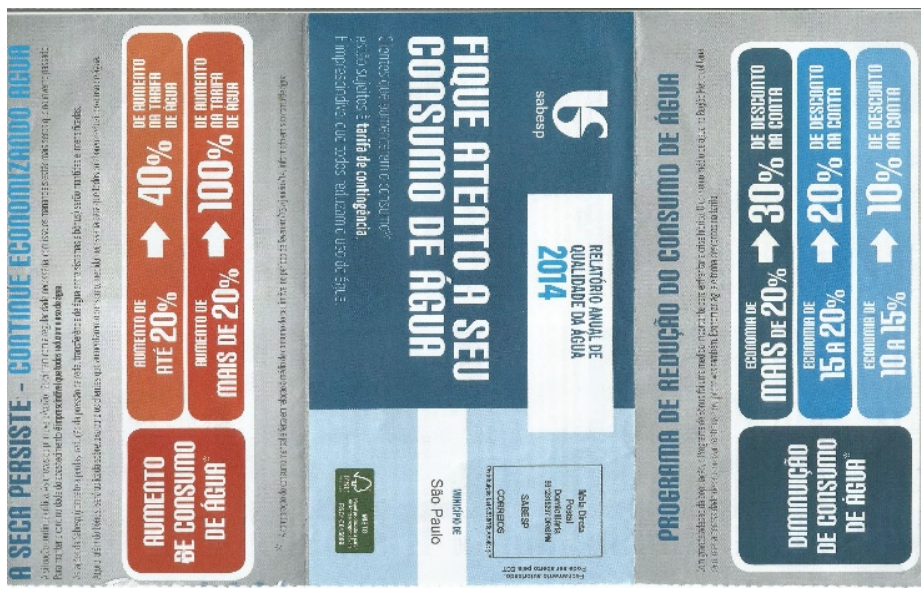

Figura 2- Reprodução da capa de mala direta enviado aos consumidores. Fonte: RELATÓRIO ANUAL DE QUALIDADE DA ÁGUA 2014(2015)

e) venda pessoal: visitas à edificações verticais, escolas, estabelecimentos comerciais e hotéis; mais de dois milhões de abordagens diretas junto a transeuntes, em locais de grande circulação, como estações de trem e metrô, parques e eventos, resultando em um fluxo impactado de 19,5 milhões de pessoas; distribuição e afixação de materiais impressos; contatos com os maiores clientes privados e com órgãos públicos, visando a uma redução do consumo de água e o estímulo à utilização

\footnotetext{
${ }^{8}$ Este relatório continha a descrição dos descontos e multas que estavam sendo auferidas, conforme a faixa de redução ou aumento de consumo de água; apresentava uma posição com relação aos diversos sistemas que abastecem o estado por meio dessa companhia de água e outras informações institucionais. Nota do autor.
} 
de água de reuso, além de parcerias com entidades, associações e organizações não governamentais, com a realização de palestras e treinamentos sobre economia de água (SABESP, 2015a; CHESS, 2015);

\begin{tabular}{|c|c|c|c|c|c|c|c|c|c|c|c|c|c|c|c|}
\hline \multicolumn{3}{|c|}{ FASE 1} & \multicolumn{5}{|c|}{ FASE $2 \nabla$} & \multicolumn{8}{|c|}{ FASE $3 v$} \\
\hline $\mathrm{ma} / 14$ & $\mathrm{JuN} / 14$ & $j u / 14$ & o50/14 & $\operatorname{set} / 14$ & out $/ 14$ & nov/14 & $\operatorname{dez} / 14$ & $\mathrm{jan} / 1 \mathrm{1S}$ & $\mathrm{fev} / 1 \mathrm{~s}$ & $\mathrm{mar} / 1 \mathrm{~s}$ & $s t r / 15$ & $\mathrm{ma} / 1 \mathrm{1s}$ & $\mathrm{jun} / 1 \mathrm{1S}$ & $j u / 15$ & $\mathrm{sg} 0 / 15$ \\
\hline \multicolumn{2}{|c|}{$\begin{array}{l}\text { Açăo de Visitas } \\
\text { Ponto a Ponto } \\
\text { em condominios } \\
\text { residenclais. }\end{array}$} & \multicolumn{3}{|c|}{$\begin{array}{l}\text { Ação de Visitas em } \\
\text { condominios, locais } \\
\text { criticos e Açăo } \\
\text { ostensiva. }\end{array}$} & \multicolumn{6}{|c|}{$\begin{array}{l}\text { Açäo de Visitas residenciais acima de } \\
25 \mathrm{~m} 3 / \text { més que aumentaram consumo nos } \\
\text { meses anteriores e açōes de abordagem em } \\
\text { locais de grande concentração. }\end{array}$} & \multicolumn{5}{|c|}{ 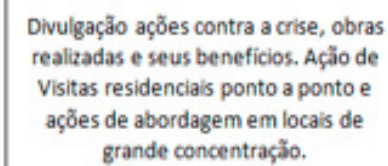 } \\
\hline
\end{tabular}

Quadro 1 - Cronograma de realização de visitas e abordagens em locais públicos. Fonte: Sabesp, 2015a.

Quase que simultaneamente, foi instituída a segunda estratégia do "Demarketing da Água": um desconto de 30\% para quem reduzisse o consumo de água em mais de $20 \%$ que foi ampliado e implementado com multas e aumentos efetivos durante o decorrer do biênio 2014/2015 (CHESS, 2015, NÍVEL..., 2014).

No início do $2^{\underline{0}}$ trimestre de 2014, essas ações já produziam efeitos significativos: $37 \%$ da população havia alcançado uma redução de $20 \%$ em seu consumo, embora uma parcela ainda significativa (24\%), contrariamente ao previsto, o tivesse aumentado (MACEDO, 2014); grandes empresas, condomínios de luxo e moradores de bairros nobres estavam entre eles, (SORANO, 2015; BAIRROS..., 2014; LEITE, 2015a), embora durante todo o período, ambientalistas tivessem realizado manifestações para o uso racional da água ('ABRAÇO'..., 2014; DIA..., 2015; SÁ, 2014).

A terceira estratégia referente ao "Demarketing da Água", também teve início, com a alteração das funções de utilidade da distribuição de água, que estavam relacionadas ao período pelo qual a água ficava disponível e aos locais para onde ela era disponibilizada. Suas principais ações foram: um "contingenciamento" do fornecimento à noite, um controle operado a partir dos registros da companhia que ora disponibilizava água para um local ora para outros e diminuía a pressão da água nas tubulações, o que fazia com que o volume de água nas torneiras não se alterasse mesmo que fossem abertas ao máximo e dificultava o armazenamento de grande quantidade de água (SABESP, 2014; PELA..., 2015; SORANO, 2015b; GARCIA; SORANO, 2015).

Em outubro de 2014 foi implementada a extensão dos descontos para quem economizasse entre 10 e 20\% (CHESS, 2015) e no final deste mesmo ano o preço da água foi aumentado em 6,5\% para todos os consumidores, estivessem estes economizando ou não (LEITE, 2015). 
Em fevereiro de 2015 foram instituídas as multas para quem consumisse qualquer quantia acima da média do ano anterior à crise (CHESS, 2015; ALCKMIN..., 2014a) e em julho, outro aumento de 15,24\% foi incrementado, resultando em um total acumulado da ordem de 22,7\%, considerando-se o que já havia sido aplicado no final de 2014 (LEITE, 2015).

Tanto para aplicar as multas como para conceder os descontos, a companhia realizou um controle que comparava o consumo mensal, de cada unidade consumidora, a partir de fevereiro de 2014, com o volume médio consumido no ano anterior - de fevereiro de 2013 a janeiro de 2014 (RELATÓRIO..., 2015).

A tabela 1 mostra como ficaram os descontos e multas.

Tabela 1 - Descontos e multas aplicados conforme aumento ou redução de consumo

\begin{tabular}{cccc}
\hline Redução de Consumo & Descontos obtidos & Aumento de Consumo Multas aplicadas \\
\hline 10 a $15 \%$ & $10 \%$ & até $20 \%$ & $40 \%$ \\
15 a $20 \%$ & $20 \%$ & $20 \%$ ou mais & $100 \%$ \\
$20 \%$ ou mais & $30 \%$ & & \\
\hline
\end{tabular}

Fonte: RELATÓRIO.... (2015)

A seguir, nas tabelas 1 e 2, apresenta-se, por meio de uma simulação, a variação que cada conta de fornecimento de água sofreu, considerando-se os aumentos efetivos e as diversas faixas de descontos e multas que foram aplicadas ao volume consumido a mais ou a menos.

Tomando-se como base uma conta com valor hipotético de $\mathrm{R} \$ 10,00$, antes da crise, a variação de preço, para quem manteve o consumo, referiu-se somente aos aumentos de preço que totalizavam $22,7 \%$, passando esta conta a ser de $\mathrm{R} \$ 12,27$, depois da crise.

Já para quem reduziu o consumo, por exemplo, em $10 \%$, o valor final da conta foi onerado em 10,44\%, uma vez que apesar dos aumentos que totalizavam 22,7\%, havia um desconto da ordem de $10 \%$. Entretanto, para quem economizou $15 \%$ ou mais, o valor da conta foi reduzido, uma vez que apesar do aumento da ordem de $22,7 \%$, houve um percentual de desconto maior do que o oferecido a quem economizasse até $10 \%$. 
Tabela 2 - Variação do preço da água depois dos aumentos e descontos

\begin{tabular}{ccccccc}
\hline $\begin{array}{c}\text { Valor da } \\
\text { conta antes } \\
\text { da crise }\end{array}$ & $\begin{array}{c}\text { Redução } \\
\text { de } \\
\text { Consumo }\end{array}$ & $\begin{array}{c}\text { Valor da } \\
\text { conta, se } \\
\text { fosse } \\
\text { reduzido o } \\
\text { consumo de } \\
\text { água em 10\%, } \\
\text { antes da crise }\end{array}$ & $\begin{array}{c}\text { Desconto } \\
\text { obtido nessa } \\
\text { conta em } \\
\text { função da } \\
\text { redução de } \\
\text { consumo }\end{array}$ & $\begin{array}{c}\text { Valor da } \\
\text { conta } \\
\text { durante a com o } \\
\text { desconto }\end{array}$ & $\begin{array}{c}\text { Valor da } \\
\text { conta com } \\
\text { o aumento } \\
\text { total de }\end{array}$ & $\begin{array}{c}\text { Variação da } \\
\text { conta em } \\
\text { relação ao } \\
\text { valor antes da } \\
\text { crise }\end{array}$ \\
\hline $\mathrm{R} \$ 10,00$ & $10 \%$ & $\mathrm{R} \$ 9,00$ & $10 \%$ & $\mathrm{R} \$ 8,10$ & $\mathrm{R} \$ 9,94$ & $+10,44 \%$ \\
$\mathrm{R} \$ 10,00$ & $15 \%$ & $\mathrm{R} \$ 8,50$ & $20 \%$ & $\mathrm{R} \$ 6,80$ & $\mathrm{R} \$ 8,34$ & $-1,88 \%$ \\
$\mathrm{R} \$ 10,00$ & $20 \%$ & $\mathrm{R} \$ 8,00$ & $30 \%$ & $\mathrm{R} \$ 5,60$ & $\mathrm{R} \$ 6,87$ & $-14,11 \%$ \\
\hline
\end{tabular}

Fonte: RELATÓRIO... (2015). Nota: Simulação, Cálculos e Análise elaborado pelo autor

Na tabela 3, também a partir de uma conta com esse valor de $R \$ 10,00$, verifica-se que no caso de um aumento de consumo o acréscimo foi significativo, pois, além do aumento total no preço da ordem de 22,7\%, houve ainda o acréscimo de multas que, embora proporcionais às faixas de consumo, eram bem maiores que os descontos concedidos a quem reduzisse o consumo.

Tabela 3 - Variação do preço da água depois dos aumentos de preço e multas

\begin{tabular}{ccccccc}
\hline $\begin{array}{c}\text { Valor da } \\
\text { conta } \\
\text { antes da } \\
\text { crise }\end{array}$ & $\begin{array}{c}\text { Aumento } \\
\text { de } \\
\text { Consumo }\end{array}$ & $\begin{array}{c}\text { Valor da } \\
\text { conta, se } \\
\text { fosse } \\
\text { aumentado } \\
\text { o consumo, } \\
\text { antes da } \\
\text { crise }\end{array}$ & $\begin{array}{c}\text { Multa } \\
\text { acrescida } \\
\text { nessa conta em } \\
\text { função de um } \\
\text { aumento de } \\
\text { consumo, } \\
\text { depois da crise }\end{array}$ & $\begin{array}{c}\text { Valor da } \\
\text { conta com } \\
\text { a multa }\end{array}$ & $\begin{array}{c}\text { Valor da } \\
\text { conta com } \\
\text { o aumento } \\
\text { de 22,7\% }\end{array}$ & $\begin{array}{c}\text { Variação da } \\
\text { conta em } \\
\text { relação ao } \\
\text { valor antes } \\
\text { da crise } \\
\text { (coluna 6/ } \\
\text { coluna 3) }\end{array}$ \\
\hline $\mathrm{R} \$ 10,00$ & $10 \%$ & $\mathrm{R} \$ 11,00$ & $40 \%$ & $\mathrm{R} \$ 15,40$ & $\mathrm{R} \$ 18,90$ & $+71,82 \%$ \\
$\mathrm{R} \$ 10,00$ & $20 \%$ & $\mathrm{R} \$ 12,00$ & $100 \%$ & $\mathrm{R} \$ 24,00$ & $\mathrm{R} \$ 29,45$ & $+145,42 \%$ \\
\hline
\end{tabular}

Fonte: RELATÓRIO... (2015) Nota: Simulação, Cálculos e Análise elaborado pelo autor

Supondo-se que essa conta de $\mathrm{R} \$ 10,00$ correspondesse ao consumo de $10 \mathrm{~m}^{3}$ de água (R\$ $1,00 \mathrm{o} \mathrm{m}^{3}$ ), se o consumidor reduzisse seu consumo em $20 \%$, antes da crise, pagaria por sua conta $\mathrm{R} \$ 8,00$, mas, durante a crise, sobre o valor referente a esse mesmo consumo, houve um aumento real de $22,7 \%$ e concessão de descontos de $30 \%$, o que fez com que os mesmos $8 \mathrm{~m}^{3}$ passassem a custar $R \$ 6,87$, ou seja, em média $R \$ 0,86$ por $\mathrm{m}^{3}\left(\mathrm{R} \$ 6,87 / 8 \mathrm{~m}^{3}\right)$, em vez de $\mathrm{R} \$ 1,00$ por $\mathrm{m}^{3}$, pagos antes da crise.

Do lado oposto, porém, se o consumidor aumentasse seu consumo em $20 \%$, antes da crise, sua conta seria de $\mathrm{R} \$ 12,00$, mas, durante a crise, sobre esse valor incidiram $22,7 \%$ 
de aumentos reais e multa de 100\%, o que fez com que o consumo dos mesmos $12 \mathrm{~m}^{3}$ tivessem passado a custar $\mathrm{R} \$ 29,45$, ou seja, em média $\mathrm{R} \$ 2,45$ por $\mathrm{m}^{3}$ ( $\left.\mathrm{R} \$ 29,45 / 12\right)$, em vez de $\mathrm{R} \$ 1,00$ por $\mathrm{m}^{3}$, pagos antes da crise.

Considerando-se essa simulação e comparando-se as duas situações verifica-se que um $\mathrm{m}^{3}$ de água para quem aumentou o consumo em $20 \%$, passou a custar, durante a crise, em média, quase o triplo $(\mathrm{R} \$ 2,45 / 0,86=284 \%)$ do que custou para o consumidor que reduziu seu consumo em $20 \%$.

Os esforços realizados foram eficazes do ponto de vista do imediatismo que a redução de consumo de água impunha. Conforme dados da companhia de água, comparando-se fev/2014 com mar/2015, “... a retirada de água do Cantareira teve uma redução de $56 \%$, o que significa uma economia de $17,73 \mathrm{~m}^{3} / \mathrm{s}$. Desta economia, $41 \%$ se deve às ações de Redução de Pressão/Controle de Perdas... e [...] 20\% ao Programa de Bônus [...], ou seja, a economia obtida derivou-se dos descontos e multas e também da alteração na forma de distribuição da água (CHESS, 2015, p. 24). Por outro lado, houve uma queda da ordem de 53\% nos lucros da companhia de água (SORANO, 2015a)

Deve-se observar que os efeitos dessa redução de consumo foram provenientes, em sua maior parte, de unidades residenciais, uma vez que unidades comerciais e industrias, principalmente as de grande porte (SORANO, 2015, LEITE, 2015a), assim como parte das unidades residenciais foram apontadas como responsáveis pelo aumento de consumo (BAIRROS..., 2014; SORANO, 2015).

Ainda é necessário lembrar que a escassez de água no Brasil apresenta outra consequência grave, pois, $70 \%$ da energia do país é gerada por água. Em uma situação de escassez de água essa energia é obtida por meios mais onerosos, provocando também um aumento de preço na energia (FURLAN; VIEIRA, 2015). Durante a crise, em apenas oito meses, o preço da energia foi elevado em 75\% (BOMFIM..., 2015).

\section{2 - Discussão e Análise das Ações Realizadas à Luz da Teoria Original de Kotler e Levy}

Quando se analisa a campanha realizada sob o cenário apresentado, algumas considerações podem ser realizadas em relação ao referencial teórico no qual este artigo se baseou.

A primeira é que quando se trata de uma campanha de demarketing é necessário não só verificar-se o tipo de campanha - geral, seletiva ou ostensiva e a situação em que ela se insere - escassez, superpopularidade crônica ou eliminação definitiva da oferta, mas 
também sua finalidade, pois essa finalidade poderá alterar quais ações e com qual sentido - demarketing ou marketing tradicional, elas deverão ser implementadas, uma vez que no "Demarketing da Água" mesmo ações com o sentido do marketing tradicional colaboraram para o alcance dos objetivos pretendidos.

Propõe-se, desta forma, que cada campanha de demarketing seja também classificada conforme sua finalidade:

- Comercial: visa, exclusivamente, a atender interesses de uma organização com fins de alguma forma lucrativos, seja devido a escassez de matériaprima, desativação de um produto, uma superpopularidade crônica do produto ou ainda o aguçamento de desejo por um bem específico.

- Social: visa a atender a um benefício específico, para a sociedade como a redução do consumo de fumo, álcool e do uso do automóvel (hábito sedentário) ou de produtos com alto teor de gordura, açúcar, sódio, lactose, glúten, entre outros, uma vez que, conforme Sodhi (2011) o "social" refere-se "à saúde e ao bem-estar".

- Ambiental: visa a atender a uma condição do ambiente, procurando reduzir o consumo de recursos naturais escassos como o petróleo, elementos da natureza como a madeira e a água, bem como os gerados por algum deles, como a energia, seja porque causam algum prejuízo, são insubstituíveis, limitados ou insuficientes para continuar a prover a humanidade no futuro. Conforme Sodhi (2011) "ambiental" está relacionado à "poluição, aos resíduos e ao uso de recursos".

A segunda questão refere-se, especificamente, a como obter redução de demanda, em campanhas classificadas por Kotler e Levy (1971), como de demarketing geral. Além da estratégia mencionada pelos autores de se reduzir a distribuição (número de distribuidores), verifica-se por este estudo que uma redução de demanda pode ser obtida por meio de uma restrição no consumo individual, quando se alteram as funções de utilidade da distribuição - tempo, local e posse (DIAS, 2003), nos casos em que o bem é essencial e não pode ser deixado de ser consumido, mas se apresenta temporariamente escasso e/ou o distribuidor é exclusivo, não podendo ser eliminado.

A terceira colocação refere-se aos instrumentos recomendados por Kotler e Levy (1971), ou seja, às estratégias que foram utilizadas na campanha estudada e relacionadas a 
cada componente do mix de marketing - promoção, distribuição e preço, conforme comentado a seguir:

a) PROMOÇÃO

Quanto ao investimento promocional, o recomendado por Kotler e Levy (1971) seria uma diminuição no budget, mas, neste caso ele foi aumentado. Isto foi possível e necessário, como também demostram Deutsch e Liebermann (1985) e Grinstein e Nisan (2006), quando se trata de uma campanha com finalidade social ou ambiental, conforme classificação sugerida neste trabalho, conscientizando-se a população, com relação à redução de consumo de determinados produtos, como o tabaco ou a água. A comunicação realizada pela companhia de água se alinhou ao que Cullwick (1975) recomenda, quando se pretende uma mudança de atitude: "o foco da propaganda deve ser criar novas atitudes que estejam relacionadas a padrões emergentes de valores sociais".

Ainda no âmbito da promoção, também foi realizada intensa ação que pode ser classificada como "venda pessoal", uma vez que incluiu contatos e distribuição de material promocional impresso, por agentes da companhia de água, com a função de orientar e esclarecer dúvidas de usuários. Essa ação pode ser aplicada em campanhas com funções sociais e ambientais. Quanto aos vendedores serem treinados para conduzir os consumidores à aquisição de produtos alternativos, como recomendam Kotler e Levy (1974), isso foi viabilizado junto a determinados consumidores, uma vez que a companhia possui um subproduto denominado "água de reuso", adequada à algumas finalidades, que anteriormente consumiam água potável. A ação de oferta alternativa de um outro produto da organização pode ser utilizada em campanhas comerciais ou ambientais dependendo da existência de produto alternativo ao que se apresenta escasso. Em campanhas sociais visualiza-se uma utilização restrita, como no caso de menor uso do automóvel, visando à condução dos motoristas à substituição de seu meio de transporte por outro, como a bicicleta, o que levaria o motorista sedentário à uma saudável prática esportiva.

b) DISTRIBUIÇÃO

Como não havia a possibilidade de se reduzir o número de distribuidores, conforme recomendação de Kotler e Levy (1971), pois a companhia de água 
realiza esta distribuição de forma exclusiva (por meio de outorga), o que se alterou foram as funções de utilidade distribuição. A água passou a estar disponível por menos tempo, a ser fornecida em menor quantidade, com uma menor pressão e ora estava disponível para alguns locais, ora para outros, além disso os descontos e multas conduziam a uma redução de posse do produto. Entende-se que a alteração das funções de utilidade (tempo e lugar) não seria viável em campanhas comerciais (a menos que se tratasse do demarketing ostensivo), pois o custo de entrega de produtos em quantidade reduzida, a um mesmo número de distribuidores, por si, elevaria seu custo; além disso, a irregularidade dessa distribuição (quando, quanto e para quem) exigiria uma gestão mais trabalhosa contribuindo igualmente para aumento de custos. Esta alteração também não se mostra muito adequada para campanhas com finalidades sociais, uma vez que para o combate a vícios como o álcool e o fumo, poderiam gerar uma corrida à aquisição e estocagem indesejável do bem, nos poucos momentos e locais que ele estivesse disponível, mas, poderiam fazer sentido para produtos com alto teor de gordura, açúcar, sal, entre outros, uma vez que a ruptura de bens no varejo, acaba por desestimular o consumidor a adquirilos e o conduz à procura de produtos alternativos. No caso de campanhas ambientais, as alterações podem ser realizadas quando houver controle do que é fornecido pela organização e consumido por seus clientes como a água, a energia elétrica e o gás.

c) PREÇO

Modificações no preço implicam em alteração na posse do produto função de utilidade da distribuição, (DIAS, 2003), por parte do consumidor. Os instrumentos que foram utilizados nessa campanha descontos, multas e aumentos efetivos, entretanto, apresentam-se como um aspecto mais complexo, em termos de análise, uma vez que, tonar-se difícil prever o que poderia acontecer se um aumento de preço significativo fosse implantado logo no início, conforme recomendam Kotler e Levy (1971) e se somente um aumento no preço seria suficiente para o nível de redução de consumo desejado ou, se esta redução, ocorreria na velocidade que era necessária. O que se verifica é que o conjunto descontos, multas e aumentos reais do preço da água, surtiram o efeito pretendido, no tempo devido, embora se entenda que descontos só devam ser utilizados em casos extremos, como na situação estudada neste trabalho, pois, se ações 
urgentes não fossem implementadas e a estiagem não abrandasse, o volume morto do maior reservatório da cidade (400 bilhões de litros de água) seria suficiente somente para abastecer a cidade até meados de 2014 (SÁ, 2014). Deve-se ainda considerar que, a despeito dos benefícios que os descontos possam auferir, a desativação da oferta de um desconto, depois de passada uma situação de crise, tende a afetar principalmente os consumidores mais sensíveis a preço e, portanto, a forma como esse desconto será suspenso deve igualmente ser estudada previamente, para não onerar, de forma repentina, principalmente, as camadas de renda inferior da população. Também se entende que descontos não se aplicariam a campanhas com finalidade comercial, nem social, uma vez que produziriam um aumento indesejado de consumo do bem cuja demanda se quer reduzir, sendo recomendados apenas em campanhas ambientais, cujo fornecimento e consumo sejam possíveis de controle. As multas podem ser uma excelente alternativa, quando há um grupo de consumidores resistentes a mudanças e/ou indiferentes a questões que podem afetar a sociedade como um todo e, neste caso, foram aplicadas aos que aumentaram o consumo, não se importando em mantê-lo, funcionando como um reforço aos aumentos. Seriam aplicáveis a finalidades sociais e ambientais também em forma de sobretaxas ou impostos, como mencionam Wright e Egan (2000), em campanha realizada para controle do uso do automóvel, quando considerado um bem poluente.

Por último, constata-se que a utilização de vários instrumentos, simultâneos, como alertam Kotler e Levy (1971), apresenta riscos e que um deles pode não ser a perda de clientes em definitivo ou sua difícil recuperação, conforme mencionam os autores, mas a redução de lucros da organização.

Em dezembro de 2015 o nível do Sistema Cantareira atingiu seu volume útil ${ }^{9}$, em função das chuvas, voltando a apresentar uma situação de normalidade (MARANHÃO, 2015).

O quadro 1, a seguir, é um resumo da análise e discussão realizadas nesta parte do estudo. Ele apresenta os componentes do mix de marketing (coluna 1- Políticas); as estratégias utilizadas no "Demarketing da Água" (coluna 2 - Ações); o sentido utilizado nas ações dessa campanha - do demarketing ou do marketing tradicional (coluna 3 -

\footnotetext{
${ }^{9}$ Atingir o volume útil significa não utilizar mais o volume morto (MARANHÃO, 2015).
} 
Sentido das Ações) e a finalidade das campanhas, nas quais as ações, com o mesmo sentido que o utilizado no "Demarketing da Água" poderiam ser aplicadas (coluna 4 Aplicação em Campanhas).

\begin{tabular}{|c|c|c|c|c|}
\hline Políticas & \multicolumn{2}{|c|}{$\begin{array}{l}\text { Ações realizadas no } \\
\text { "Demarketing da } \\
\text { Água" }\end{array}$} & $\begin{array}{l}\text { Sentido da realização } \\
\text { das ações no } \\
\text { “Demarketing da } \\
\text { Água" }\end{array}$ & $\begin{array}{l}\text { Aplicação das ações do } \\
\text { "Demarketing da Água" } \\
\text { em campanhas de } \\
\text { demarketing, conforme } \\
\text { sua finalidade }\end{array}$ \\
\hline Distribuição & \multicolumn{2}{|c|}{$\begin{array}{l}\text { Alteração das funções } \\
\text { de utilidade da } \\
\text { distribuição (tempo e } \\
\text { lugar) }\end{array}$} & Demarketing & $\begin{array}{l}\text { - Ambientais (1) } \\
\text { - Comerciais (2) } \\
\text { - Sociais (3) }\end{array}$ \\
\hline \multirow[t]{3}{*}{ Preço } & \multicolumn{2}{|c|}{ Desconto } & Marketing Tradicional & - Ambientais (1) \\
\hline & \multicolumn{2}{|c|}{$\begin{array}{l}\text { Multas (ou sobretaxas/ } \\
\text { impostos) }\end{array}$} & Demarketing & $\begin{array}{l}\text { - Sociais } \\
\text { - Ambientais }\end{array}$ \\
\hline & \multicolumn{2}{|c|}{ Aumento de preço } & Demarketing & $\begin{array}{l}\text { - Comerciais } \\
\text { - Sociais } \\
\text { - Ambientais }\end{array}$ \\
\hline \multirow{3}{*}{$\begin{array}{l}\text { Promoção } \\
\text { (Aumento no } \\
\text { budget } \\
\text { Promocional) }\end{array}$} & \multicolumn{2}{|c|}{$\begin{array}{l}\text { Comunicação impressa } \\
\text { e veiculação na mídia }\end{array}$} & Marketing Tradicional & $\begin{array}{l}\text { - Sociais } \\
\text { - Ambientais }\end{array}$ \\
\hline & \multirow{2}{*}{$\begin{array}{l}\text { Venda } \\
\text { Pessoal }\end{array}$} & $\begin{array}{l}\text { Informativa } \\
\text { e Educativa }\end{array}$ & Marketing Tradicional & $\begin{array}{l}\text { - Sociais } \\
\text { - Ambientais }\end{array}$ \\
\hline & & $\begin{array}{l}\text { Oferta de } \\
\text { bem } \\
\text { alternativo }\end{array}$ & Demarketing & $\begin{array}{l}\text { - Comerciais (4) } \\
\text { - Ambientais (4) } \\
\text { - Sociais (5) }\end{array}$ \\
\hline
\end{tabular}

Quadro 1 - Ações realizadas pela Companhia de Água e sua Aplicação a campanhas de demarketing conforme sua finalidade, proposta neste trabalho. Fonte: Elaborado pela autora.

Legenda do quadro:

(1) Para campanhas que envolvam produtos possíveis de controle de fornecimento/consumo, como água, energia, gás.

(2) Possível para campanhas de demarketing ostensivo

(3) Não indicado para consumo de bens ligados a vício, mas possível, por meio de aumento de impostos e sobretaxas, para produtos pouco recomendados como os que apresentam alto teor de sal, açúcar, etc.

(4) Dependente da organização ter produto alternativo para oferecer ao mesmo mercado.

(5) Aplicação restrita

\section{CONCLUSÃO}

O presente trabalho se propôs a analisar a campanha empreendida pela companhia de água responsável pelo abastecimento da cidade e pelo governo do estado de São Paulo, durante uma crise de abastecimento causada, em princípio, por motivos climáticos, que apresentava ações caracterizáveis como uma campanha de demarketing. A população 
pega de surpresa, com a iminente falta de água anunciada pela mídia, em um período típico de enchentes, se viu, de repente, conduzida a reduzir seu consumo e mudar sua atitude, mas, principalmente, seu comportamento com relação a forma como consumia água, até então. Não foi objeto deste estudo a verificação se, e até que ponto, a atitude dos consumidores foi modificada, mas os dados relacionados ao nível de economia alcançado sugerem que o comportamento tenha sido alterado, durante esse período (2014-2015).

A principal contribuição deste trabalho foi analisar esta campanha sob a visão de uma campanha de demarketing, raramente descrita em trabalhos científicos, além de apresentar como as ações foram implantadas - contrárias, por vezes, às recomendações de Kotler e Levy (1971): a) oferta de descontos, aplicação de multas e aumento de preços, quando o recomendado para ações de demarketing seria somente o aumento de preço; b) alteração das funções de utilidade da distribuição, apesar de o indicado ser a redução dos distribuidores, quando essa redução não for possível devido à distribuição ser realizada em caráter de exclusividade e/ou quando o bem for essencial e não puder ser suprimido; c) aumento do budget promocional no lugar de sua redução, quando a objetivo for a conscientização do público alvo e a condução das ações de venda para a aquisição de outro produto, substituível, quando houver disponibilidade de oferta alternativa, como a "água de reuso" no caso estudado.

Apesar de algumas dessas ações terem sido realizadas no sentido do marketing tradicional, elas mostraram eficácia e podem servir de referência para outras campanhas de demarketing, especialmente em casos de urgência, otimizando o alcance dos objetivos desejados, embora se deva considerar que conforme alertado por Kotler e Levy (1971), quando há utilização de várias ações de forma simultânea, seus efeitos podem ser cumulativos e trazer algum prejuízo, como a superinibição de clientes, ou, como visto neste estudo, uma redução nos lucros da organização.

A análise da campanha também gerou uma sugestão de classificação de campanhas de demarketing por finalidade e permitiu uma análise sobre a adequação das ações e sentidos adotados na campanha "Demarketing da Água", em relação às finalidades propostas. Essa análise serve como uma sinalização - possível ou não de ser aplicada, em futuras ações de demarketing, conforme a finalidade que cada uma tiver.

\section{LIMITAÇÕES DO ESTUDO}

A principal limitação deste estudo é o fato de ter se apoiado apenas em dados secundários disponíveis, que eram abundantes em relação ao que ocorria com a água, mas que nem sempre apresentavam detalhes das ações realizadas, como seria o desejado, o que conduz a sugestão de que um estudo de caso descritivo (YIN, 2001) venha a ser realizado, 
fornecendo dados e informações com detalhes que não se conseguiu obter nas publicações disponíveis.

Também se endente que uma investigação conclusiva do tipo descritiva (MALHOTRA, 2001) seria importante para identificar quais dos fatores - descontos e multas; alteração das funções de utilidade da distribuição ou ações promocionais, surtiram mais efeito junto ao consumidor e quanto elas influíram não somente na mudança de seu comportamento mas também de sua atitude, uma vez que a tendência, em casos de mudança apenas de comportamento é que finda a crise este volte a ser o anterior, o que no caso seria o de desperdício do bem em questão, quando o prioritário, seria a adoção de uma atitude mais consciente, se refletindo em um comportamento de consumo responsável e permanente.

Além disso, deve-se lembrar que a análise se restringiu a comentar a campanha, caracterizável como uma ação de demarketing e, por isso, denominada "Demarketing da Água", não incluindo outras ações realizadas pela companhia responsável pelo abastecimento da região, bem como pelo governo do estado, destinadas à uma melhoria no nível de abastecimento. Também não se destinou a analisar qualquer outra providência/ação que poderia ter sido empreendida e, consequentemente, implicado em uma gestão da crise diferente da que foi realizada por seus gestores.

\section{Referências bibliográficas}

"ABRAÇO" na represa de Guarapiranga alerta para problema de abastecimento em SP. Agência Brasil, 11 jun. 2014. Disponível em: http://ultimosegundo.ig.com.br/brasil/sp/201406-01/abraco-na-represa-de-guarapiranga-alerta-para-problema-de-abastecimento-emsp.html. Acesso em 18 jun. 2015

ÁGUA. Qual é a fonte? Exame, ed. 1086, a. 49, n. 6, 01 abr. 2015. Informe Publicitário.

ALCKMIN inaugura obra para captar volume morto do Sistema Cantareira. IG São Paulo, 16 jun. 2014. Disponível em: http://ultimosegundo.ig.com.br/brasil/sp/2014-05-15/alckmininaugura-obra-para-captar-volume-morto-do-sistema-cantareira.html. Acesso em: 18 jun.2015.

ALCKMIN anuncia multa para quem aumentar consumo de água em SP. IG São Paulo, 18 dez. 2014a. Disponível em: http://ultimosegundo.ig.com.br/brasil/2014-12-18/alckminanuncia-multa-para-quem-aumentar-consumo-de-agua-em-sp.html. Acesso em 18 jun. 2015. 
ANDREWS, J. Craig, NETEMEYER, Richard G., BURTON, Scot, MORBERG, D. Paul, CHRISTIANSEN, Ann. Understanding adolescents intentions to smoke: an examination of relationships among social influence, prior trial behavior, and antitobacco campaingn advertising. Journal of Marketing, v. 68, n 3, p. 110-23, 2004.

ARMSTRONG, E. Kate, KERN, Christine L. Demarketing manages visitor demand in the Blue Mountains National Park. Journal of Ecotourism, v.10, ed. 1, 2011. Disponível em: http://www.tandfonline.com/doi/abs/10.1080/14724040903427393. Acesso em: 05 abr. 2017.

BAIRROS nobres são os que menos economizam água na capital paulista, diz Sabesp. IG São Paulo, 28 ago. 2014. Disponível em: http://ultimosegundo.ig.com.br/brasil/sp/2014-0828/bairros-nosbre-sao-os-que-menos-economizam-agua-na-capital-paulista-dizsabesp.html. Acesso em 18 jun. 2015.

BEETON, S.; PINGE I. Casting the holiday dice: Demarketing gambling to encourage local tourism. Current Issues in Tourism, v. 6, n. 4, p. 309-322, 2003.

BOMFIM, Mariana. Erro do governo e seca fizeram luz subir $42 \%$ no ano, dizem especialistas. FOLHA UOL. 04 jul. 2015. Disponível em: http://economia.uol.com.br/noticias/redacao/2015/07/04/erro-do-governo-e-seca-fizeramluz-subir-42-no-ano-dizem-especialistas.htm. Acesso em: 16 jul. 2015.

CHESS - Crise Hídrica, Energética e Soluções da Sabesp. SABESP, 30 abr. 2015. Disponível em: http://site.sabesp.com.br/site/uploads/file/crisehidrica/chess_crise_hidrica.pdf . Acesso em 16 abr. 2017.

CULLWICK, David. Positioning Demarketing Strategy. Journal of Marketing, v.39, p. 51-57, Apr. 1975.

DEUTSCH, Joseph, LIEBERMANN, Yehoshua. Effects of a public advertising campaign on consumer behavior in a demarketing situation. International Journal of Research in Marketing, v.2, n.4, p.287-290, 1985.

DIA Mundial da Água: Sociedade civil se mobiliza para torneira não secar. 22 mar.15. $B B C$, 22 mar. 2015. Disponível em: http://ultimosegundo.ig.com.br/brasil/seca/2015-0322/dia-mundial-da-agua-sociedade-civil-se-mobiliza-para-torneira-nao-secar.html. Acesso em 18 jun. 2015.

DIAS, Sérgio R. Estratégia e canais de Distribuição. São Paulo: Atlas, 2003. 
ENTENDA o que é o volume morto do Sistema Cantareira. G1. Globo. 15 mai. 2014. Disponível em: http://g1.globo.com/sao-paulo/2014/05/entenda-o-que-e-o-volume-mortodo-sistema-cantareira. Acesso em 20 jun.2015.

FURLAN, Flávia; VIEIRA, Renata. A vida sem água. Exame, ed. 1083, a. 49, n.3, p.20-31, 18 fev. 2015.

GARCIA, Carolina, SORANO, Vitor. Sabesp corta água em SP e não só reduz pressão, denunciam técnicos da empresa. IG São Paulo, 06 fev. 2015. Disponível em: http://ultimosegundo.ig.com.br/brasil/seca/2015-02-06/sabesp-corta-agua-em-sp-e-nao-soreduz-pressao-denunciam-tecnicos-da-empresa.html. Acesso em 18 jun. 2015.

GESTNER, E., HESS, J.; CHU, W. Demarketing as a differentiation strategy. Marketing Letters, v. 4, n. 1, p. 49-57, Jan. 1993.

GORDON, Ian. Relationship demarketing: managing wasteful or worthless customer relationships. Ivey Business Journal Online, mar-apr. 2006. Disponível em: http://iveybusinessjournal.com/publication/relationship-demarketing-managing-wastefulor-worthless-customer-relationships/. Acesso em: 18 abr. 2017.

GRINSTEIN, Amir, NISAN, Udi. Demarketing, Minorities, and National Attachment. Journal of Marketing, v. 73, p. 105-122, mar. 2009.

GROOF, Christopher. Demarketing in park and recreation management. Managing Leisure, v. 3, n. 3, p. 128-135, 1998.

INNESS, M; BARLING J., ROGERS, K., TURNER, N. Demarketing tobacco through price changes and consumer attemps quit smoking. Journal of Business Ethics, V.77, n. 4, p. 405416, 2007.

KOTLER, Philip; LEVY, Sidney J. Demarketing, yes, demarketing. Harvard Business Review, v. 79, n. 6, p. 74-80, nov-dez. 1971.

KOTLER, Philip. Administração de Marketing: análise, planejamento e controle. São Paulo: Atlas, 1986.

KOTLER, Philip. Marketing during periods of shortage. Journal of Marketing, v. 38, n. 3, p. 20-29 July 1974.

KOTLER, Philip, ZALTMAN, Gerald. Social Marketing: An Approach to Planned Social Change. Journal of Marketing, v. 35, p.3-12, jul. 1971. 
LAWTHER, S. HASTINGS, G. B., LOWRY, R. Demarketing: putting Kotler and Levy's ideas into practice. Journal of Marketing Management, v. 13, n. 4, p. 315-325, 1997.

LEITE, Fabio. Conta de água fica 15,24\% mais cara nesta quinta-feira. O Estado de São Paulo. 03 jun. 2015. Disponível em http://sao-paulo.estadao.com.br/noticias/geral,conta-de-aguafica-15-24-mais-cara-nesta-quinta-feira,1699962. Acesso em 14 jun. 2015.

Sabesp divulga lista de grandes consumidores de água. EXAME, 10 mar.2015a. Disponível em: http://exame.abril.com.br/brasil/sabesp-divulga-lista-degrandes-consumidores-de-agua. Acesso em 14 jun.2015.

MACEDO. Letícia. Desconto para Economia de água passa a valer em 31 cidades de S.P. G1. Globo, 31 mar. 2014. Disponível em: http://g1.globo.com/sao-paulo/noticia/2014/03/saopaulo-amplia-desconto-para-quem-economizar-agua.html. Acesso em 18 jun. 2015.

MALHOTRA, Naresh K. Pesquisa de Marketing: uma orientação aplicada. Porto Alegre: Bookman, 2001. 3.ed.

MARANHÃO, Fabian. Após mais de um ano e meio, Cantareira sai do volume morto. UOL, 30 dez. 2015. Disponível em: http://noticias.uol.com.br/cotidiano/ultimasnoticias/2015/12/30/apos-mais-de-um-ano-e-meio-cantareira-sai-do-volume-morto.htm.

Acesso em 30 dez. 2015.

MARC, Annabelle. De-marketing - a Strategy of rationing for Equity? Setting Priorities in Health Care, M. Malek, John Wiley \& Sons Ltd., p. 127-140

MEDWAY, Dominic; WARNABY, Gary; DHARNI, Sheetal. Demarketing places: Rationales and strategies. Journal of Marketing Management, v. 27, p. 124-142, 2010.

MENON, A, MENON, A. Enviropreneurial marketing strategy: when and how do they work. Journal of Marketing, v.61, n.1, p.51-67, 1997.

MOWEN, John C.; MINOR, Michael. Consumer Behavior. Upper Saddle River, New Jersey: Prentice Hall, 1998.

MUNISH, Gupta, PAYAL, Gupta, PRIYA, Gupta. Demarketing - A Different Marketing Strategy to sustain the Consumers. Advances in Management, v. 7, n. 12. p. 41-45, Dec. 2014.

NIVEL de água no sistema Cantareira volta a cair e registra pior marca: $15,2 \%$. IG São Paulo, 16 mar. 2014. Disponível em: http://ultimosegundo.ig.com.br/brasil/sp/2014-03- 
16/nivel-de-agua-no-sistema-cantareira-volta-a-cair-e-registra-pior-marca-152.html. Acesso em 18 jun. 2015.

PECHMAN, Cornelia, ZHAO, Guangzhi, GOLDBERG, Marvin E., REIBLING, Ellen Thomas. What to convey in antismoking advertisements for adolescents: the use of protection motivation theory to identify effective message themes". Journal of Marketing, v. 67, n. 2. p. 1-18, 2003.

PELA primeira vez, Alckmin admite racionamento de água em SP. Agência Brasil, 14 jan. 2015. Disponível em: http://ultimosegundo.ig.com.br/brasil/2015-01-14/alckmin-admiteracionamento-de-agua-em-sp.html. Acesso em 18 jun. 2015.

RANGAN; Kasturi; KARIM Sohel; SANDBERG, Sheryl. Do Better at Doing Good. Harvard Business Review, v. 74, n. 3, pg. 45-54, 1996.

RELATÓRIO Anual de Qualidade da Água 2014. SABESP, 2015.

REPRESAS no Limite ameaçam três cidades de São Paulo. Agência Estado, 12 jan. 2010. Disponível em: http://ultimosegundo.ig.com.br/brasil/represas-no-limite-ameacam-trescidades-de-sao-paulo/n1237591493783.html. Acesso em: 18 jun.2015.

ROCHA. Daniela. Torneiras Secas. América Economia, n. 439, p. 28-32, set. 2014.

SÁ, Clarice. Dia Mundial da Água: saiba como reduzir o consumo dentro de casa. IG São Paulo, 22 mar. 2014. Disponível em: http://ultimosegundo.ig.com.br/brasil/2014-03-22/diamundia-da-agua-saiba-como-reduzir-o-consumo-dentro-de-casa. Acesso em 18 jun. 2015.

SABESP admite falta de água em S.Paulo. Agência Brasil, 08 out. 2014. Disponível em: http://ultimosegundo.ig.com.br/brasil/sp/2014-10-08/presidenta-da-sabesp-admite-faltade-agua-em-sao-paulo.html. Acesso em 18 jun. 2015

SABESP. 30 abr. $2015 . \quad$ Sabesp. Disponível em: http://site.sabesp.com.br/site/imprensa/noticias-detalhe.aspx?secaold=66\&id=6450; acesso em 11 nov. 2016.

abr. 2015a.

Sabesp.

Disponível

em:

http://site.sabesp.com.br/site/interna/Default.aspx?secaold=607. Acesso em 11 nov. 2016

SABESP disponibiliza no site período em que morador terá redução de água. Folha Uol, 27 jan. 2015b. Disponível em: http://www1.folha.uol.com.br/cotidiano/2015/01/1581045sabesp-disponibiliza-periodo-em-que-morador-tera-reducao-de-agua-na-rede.shtml. Acesso em: 02 jul. 2015. 
SEM chuvas, Sabesp faz alerta para falta de água em São Paulo. IG São Paulo, 29 jan. 2014. Disponível em: http://ultimosegundo.ig.com.br/brasil/2014-01-29/sem-chuvas-sabesp-fazalerta-para-falta-de-agua-em-sao-paulo. Acesso em 18 jun. 2015.

SHALOM, David. "Paga-se muito pouco pela água no Brasil", diz chefe do comitê da ONU. IG São Paulo, 15 nov. 2014. Disponível em: http://ultimosegundo.ig.com.br/brasil/2014-11-15/paga-se-muito-pouco-pela-agua-nobrasil-diz-chefe-do-comite-da-onu.html. Acesso em 18 jun. 2015.

SHEET, Jagdush N.; MITTAL, Banwari, NEWMAN, Bruce L. Customer Behavior: consumer behavior and beyond. Orlando: Dryden Press, 1999.

SHIFFMAN; Leon G., Leslie L. KANUK. Consumer Behavior. Upper Saddle River, New Jersey: Prentice-Hall, 2000.

SHIU, Edward, HASSAN, Louise M. WALSH, Gianfranco. Demarketing tobacco through governamental policies - The 4Ps revisited. Jounal of Business Research, v. 62, n. 2, p. 269278, Feb. 2009.

SODHI, Kamaljit. Has marketing come ful circle? Demarting for sustainability. Business Strategies Series, v. 12, n. 4, pg. 177-185, 2011.

SOLOMON, Michael R. Consumer Behavior: buying, having, and being. Englewwod Cliffs, New Jersey: Prentice Hall,1996.

SORANO, Vitor. Bairro nobre tem maior consumo de água em S. Paulo; periférico leva mais multas. IG São Paulo, 10. abr. 2015. Disponível em: http://ultimosegundo.ig.com.br/brasil/seca/2015-04-10/bairro-nobre-tem-maior-consumode-agua-em-sao-paulo.html. Acesso em 18 jun. 2015.

Lucro da Sabesp despenca 53\% em ano de crise. IG São Paulo, 26 mar. 2015a. Disponível em: http://ultimosegundo.ig.com.br/brasil/seca/2015-03-26/lucro-da-sabespdespenca-53-em-ano-de-crise.html. Acesso em 18 jun. 2015.

. Secretário nega corte de água em São Paulo, mas admite "intervenção física". IG São Paulo, 13 fev. 2015b. Disponível em: http://ultimosegundo.ig.com.br/brasil/seca/2015-02-13/secretario-nega-corte-de-agua-emsao-paulo-mas-admite-intervencao-fisica.html. Acesso em 18 jun. 2015.

SUH, Munshik, RHO, Taeseok, GREENE, Henry. Relationsip behavior between customers and service providers in demarketing situations: what makes customers try to improve 
their relationships? Journal of Database Marketing \& Customer Strategy Management, v. 19, n. 1, pg. 39-55, mar. 2012.

WALL, Anthony P. Government demarketing: diferents approaches and mixed messages. European Journal of Marketing, v. 39, n. 5/6, p. 421-427, 2005.

WRIGHT, C.C; EGAN, J. De-marketing the car. Transport Policy, v. 7, n. 4, p. 287-94, 2000.

YIN, Robert K. Estudo de Caso: Planejamento e Métodos. Porto Alegre: Bookman, 2001. 2ª̀.ed. 